\title{
Relationships between platelet function tests in normal and uraemic subjects
}

\author{
A. A. hasSAnein, G. P. McNiCOL, AND A. S. DOUGlas \\ From the University Department of Medicine, Glasgow Royal Infirmary
}

SYNOPSIS In tests of platelet function in normal subjects, the following relationships were found: the greater the platelet adhesiveness the less the ability to disaggregate after challenge with adenosine diphosphate (ADP), and the greater the disaggregation after ADP, the longer the clotting time in the test for platelet factor 3 availability. Such correlations were disturbed in uraemic patients.

In recent years many platelet function tests have been devised to study platelet behaviour in vitro. The ability of platelets to adhere to foreign surfaces, their subsequent aggregation, and their contribution of phospholipid to the intrinsic coagulation mechanism are thought to be important factors in the formation of haemostatic plugs and of thrombi. The identification of adenosine diphosphate (ADP) as a key substance in causing aggregation and adhesiveness of platelets and release of platelet factor 3 has contributed much to the understanding of platelet function.

The present investigation was carried out to determine whether there was a relationship between platelet adhesiveness, ADP-induced platelet aggregation, and platelet factor 3 availability, in normal subjects and in uraemic patients, a group in whom a qualitative platelet defect has recently been described (Lewis, Zucker, and Ferguson, 1956; Rath, Maillard, and Schreiner, 1957; Stewart and Castaldi, 1967; Hassanein, McNicol, Kennedy, and Douglas, 1969).

\section{Materials and Methods}

Blood was collected from both normal healthy subjects and uraemic patients by clean vene- puncture, using $1 \frac{1}{2}$ in. disposable needles (21 gauge) and plastic disposable syringes. The blood was immediately mixed with $3.8 \%$ sodium citrate in $10 \mathrm{ml}$ siliconized centrifuge tubes (1 part citrate to 9 parts blood). Platelet-rich plasma was prepared by centrifugation of citrated blood at $600 \mathrm{~g}$ for five minutes at room temperature. Adenosine5-diphosphate (ADP) was used in the form of the sodium salt as supplied by Sigma Chemical Company, St. Louis. The compound was dissolved in barbitone buffered saline, $p \mathbf{H} 7 \cdot 2$, and used in a final concentration of $0 \cdot 25 \mu \mathrm{g} / \mathrm{ml}$.

Platelet adhesiveness was determined in whole blood by the glass bead column method of Hellem (1960) as modified by Hirsh, McBride, and Dacie (1966).

The packed cell volume (PCV) was measured from citrated blood and appropriate corrections were made in the measurement of adhesiveness, for variations in PCV using an appropriate standard curve.

Adenosine diphosphate-induced platelet aggregation was assessed by the method of Born and Cross (1963). Platelet-rich plasma $(1.9 \mathrm{ml})$ was placed in a Perspex cuvette with a magnetic stirring rod on an EEL (Evans Electroselenium) titrator; $0 \cdot 1 \mathrm{ml}$ ADP solution was added and a stop watch was started. Changes in light transmission using a green filter (no. 604, peak length 5,200 Angstrom units) were recorded by taking optical density readings every 30 seconds for 10 minutes. All experiments were carried out at room temperature. 


\section{Assessment of Platelet Aggregation and Disaggregation}

The assessments of platelet aggregation and disaggregation were expressed as follows:

\section{0-60 PLATELET AGgREGATION}

This is the fall in optical density between 30 and 60 seconds after the addition of ADP, this being the steepest part of the curve.

\section{0-90 PLATELET AGgREgation}

The fall in optical density between 30 and 90 seconds after the addition of ADP, to include the main part of the optical density fall due to aggregation.

MAXIMUM AGGREGATION

This is measured by subtracting the lowest optical density reading from the optical density before the addition of the aggregating agent $(0 \cdot 600)$.

\section{PERCENTAGE DISAGGREGATION}

This was calculated as (increase in optical density in the five minutes from the point of maximum aggregation $\times 100) \div$ (fall in optical density from before addition of the aggregating agent to the point of maximum aggregation).

The method used to measure platelet factor 3 availability was similar to that described by Spaet and Cintron (1965). To $0.9 \mathrm{ml}$ of platelet-rich plasma was added $0.1 \mathrm{ml} 5 \%$ kaolin in a siliconized graduated centrifuge tube. The two reagents were mixed by gentle shaking 10 times and then

\begin{tabular}{|c|c|c|c|c|}
\hline $\begin{array}{l}\text { Subject } \\
\text { No. }\end{array}$ & $\operatorname{Sex}$ & Age & Diagnosis & $\begin{array}{l}\text { Blood } \\
\text { Urea } \\
\text { (mg per } \\
100 \mathrm{ml} \text { ) }\end{array}$ \\
\hline 1 & $\mathbf{M}$ & 20 & $\begin{array}{l}\text { Chronic renal failure, congenital hypoplasia of } \\
\text { kidneys }\end{array}$ & 153 \\
\hline $\begin{array}{l}2 \\
3\end{array}$ & $\begin{array}{l}\mathbf{M} \\
\mathbf{F}\end{array}$ & $\begin{array}{l}31 \\
24\end{array}$ & $\begin{array}{l}\text { Chronic renal failure, chronic glomerulonephritis } \\
\text { Chronic renal failure, congenital hypoplasia of the }\end{array}$ & 168 \\
\hline 4 & & & kidneys & 155 \\
\hline 5 & $\mathbf{F}$ & 53 & $\begin{array}{l}\text { Acute renal failure, bronchopneumonia } \\
\text { Acute renal failure, cholangitis }\end{array}$ & 290 \\
\hline 6 & $\mathbf{M}$ & 13 & $\begin{array}{l}\text { Acute renal failure, cholangitis } \\
\text { Chronic renal failure, chronic pyelonephritis }\end{array}$ & $\begin{array}{l}310 \\
131\end{array}$ \\
\hline 7 & $\mathbf{F}$ & 25 & $\begin{array}{l}\text { Spina bifida, chronic renal failure, chronic } \\
\text { pyelonephritis }\end{array}$ & 120 \\
\hline 8 & $\mathbf{F}$ & 57 & $\begin{array}{l}\text { Chronic renal failure, chronic pyelonephritis } \\
\text { myxoedema }\end{array}$ & 87 \\
\hline 9 & $\mathbf{M}$ & 58 & Chronic renal failure, hydronephrosis & 203 \\
\hline 10 & $\mathbf{F}$ & 42 & Chronic renal failure, chronic pyelonephritis & 169 \\
\hline 11 & $\mathbf{F}$ & 37 & Chronic renal failure, renal tuberculosis & 106 \\
\hline 12 & $\mathbf{M}$ & 32 & Chronic renal failure, chronic pyelonephritis & \\
\hline 13 & $\mathbf{F}$ & 53 & Chronic renal failure, acute postrenal obstruction & 300 \\
\hline 14 & $\mathbf{M}$ & 63 & Chronic renal failure, acute postrenal obstruction & 650 \\
\hline 15 & $\mathbf{M}$ & 86 & Chronic renal failure, acute postrenal obstruction & 920 \\
\hline 16 & $\mathbf{M}$ & 49 & Chronic renal failure, polycystic kidney & 360 \\
\hline 17 & $\mathbf{M}$ & 65 & $\begin{array}{l}\text { Chronic renal failure, bronchopneumonia, } \\
\text { bronchial carcinoma }\end{array}$ & 270 \\
\hline 18 & $\mathbf{M}$ & 31 & Chronic renal failure, unknown aetiology & 280 \\
\hline 19 & $\mathbf{M}$ & 55 & Chronic renal failure, epiderolysis bullosa & 190 \\
\hline 20 & $\mathbf{M}$ & 23 & Chronic renal failure, chronic glomerulonephritis & 154 \\
\hline
\end{tabular}

Table Clinical data of uraemic patients left undisturbed in a water bath at $37^{\circ} \mathrm{C}$ for $30^{-}$ minutes. After incubation, the platelet-rich plasma and kaolin were mixed by resuspending the kaolin using a siliconized pipette; $0.1 \mathrm{ml}$ of the mixture was added to $0.1 \mathrm{ml} 0.025 \mathrm{M}$ calciun chloride and $0 \cdot 1 \mathrm{ml}$ Russell viper venom $(10 \mu \mathrm{g} / \mathrm{ml}$ and the clotting time determined in duplicate The kaolin cephalin clotting time (Biggs and Macfarlane, 1966) was used as a simple screening. test to detect plasma coagulation defects irf uraemic patients. Platelet counts were performed according to the method of Dacie (1956).

Twenty uraemic patients were studied; of these two were in acute renal failure and 18 had chronie uraemia (Table).

Results

RELATIONSHIP BETWEEN PLATELET AD은 HESIVENESS AND ADP-INDUCED PLATELET AGGREGATION AND ITS REVERSAL

\section{Normal controls}

Platelet adhesiveness to glass was assessed in 170 normal controls (mean platelet-rich plasma platelet count $366,000 \pm 63,000 / \mathrm{cmm}$ ) togethes with ADP-induced platelet aggregation from the same blood sample. No correlation existed between platelet adhesiveness and platelet aggre $\frac{2}{D}$ gation as measured by $30-60,30-90$, or maximum aggregation $(r=0.0317, \mathrm{P}>0.1 ; \mathrm{r}=0.014$ 응 $P>0.1 ; \mathrm{r}=0.056, \mathrm{P}>0.1$ respectively). How ever, there was a significant negative correlation between percentage disaggregation and percentage adhesiveness $(\mathrm{r}=-0.549, \mathrm{P}<0.05)$ as shown if Figure 1. The negative correlation between pero centage platelet adhesiveness and percentage disaggregation became more significant afteo correcting the results of platelet adhesiveness for $\operatorname{PCV}(\mathrm{r}=-0.611, \mathrm{P}<0.01)$ shown in Figure 2 ?

\section{Uraemic patients}

As platelet aggregation and disaggregation weres found to be dependent on the platelet-rich plasma count (Hassanein et al, 1969), the results from 18 uraemic patients having a platelet count withirw the normal range \pm 2 SD were chosen. No cor? relation was found between platelet aggregation and disaggregation and platelet adhesiveness.

Fourteen of 18 patients showed an abnorma $P^{f}$ platelet adhesiveness-disaggregation relation -0 ship, ie, an undue decrease in either adhesivenese or disaggregation or both. The relationship? between percentage platelet adhesiveness an $\$$ percentage platelet disaggregation was still ing significant when the results of platelet adhesive ness were corrected for packed cell volumeo However, only eight patients, compared with 14 before correction, showed an abnormal relation ship. 


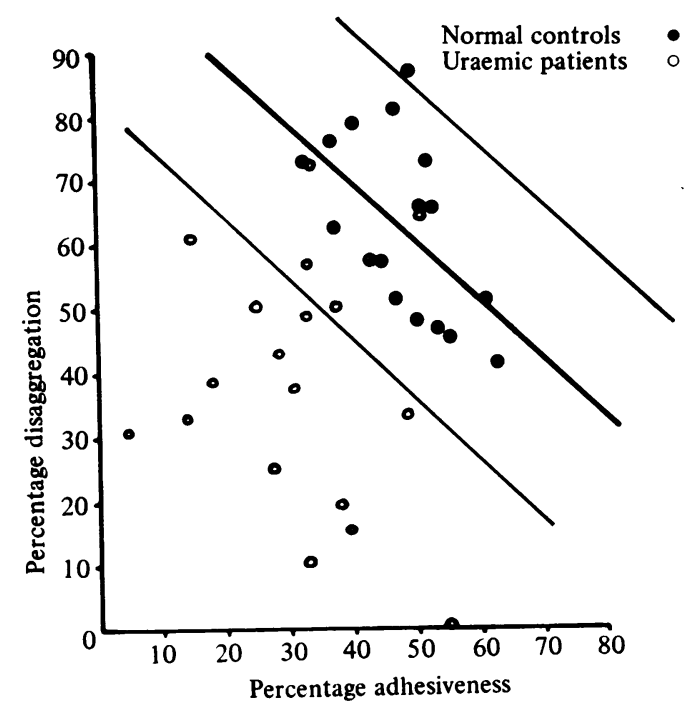

Fig. 1 The relationship between platelet adhesiveness and platelet disaggregation in normal controls and in uraemic patients. The regression line and $95 \%$ confidence limits shown are derived from the control subjects.

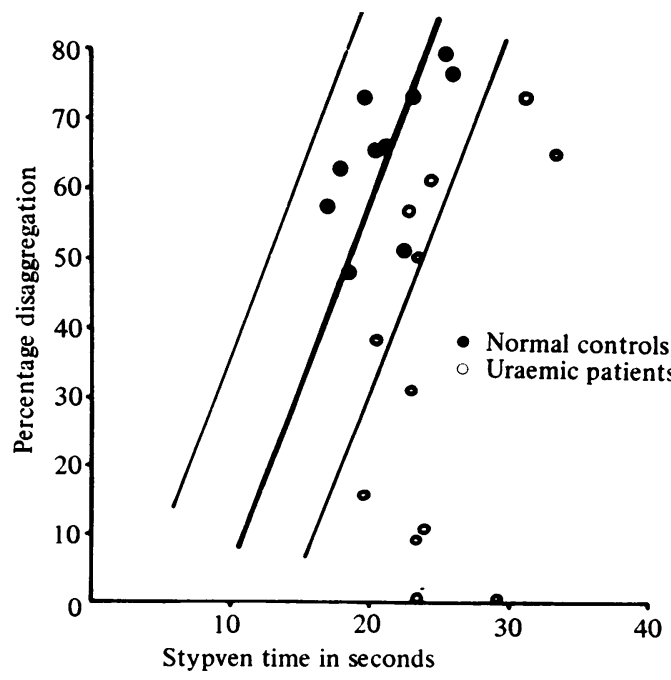

Fig. 3 The relationship between the Stypven time and platelet disaggregation in normal controls and uraemic patients. The regression line and $95 \%$ confidence limits shown are derived from the control subjects.

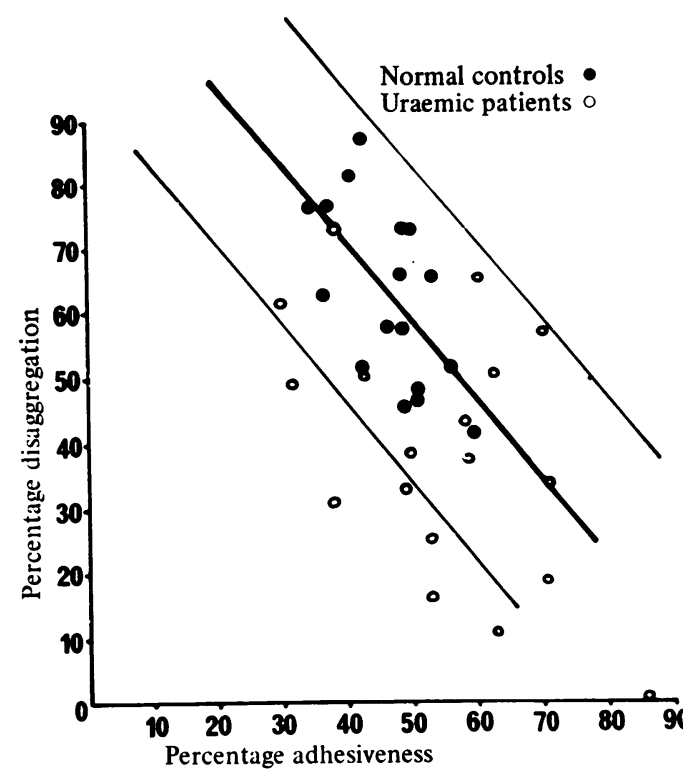

Fig. 2 The relationship between platelet disaggregation and platelet adhesiveness after correcting for PCV in normal controls and uraemic patients. The regression line and $95 \%$ confidence limits shown are derived from the control subjects.

RELATIONSHIP BETWEEN FACTOR 3 AVAILA BILITY ('STYPVEN' TIME) AND ADP-INDUCEDO' PLATELET AGGREGATION ANDITS REVERSA

\section{Normal controls}

Ten experiments were carried out in which plateleth factor 3 availability was assessed together with ADP-induced platelet aggregation from the same blood sample. No correlation was found between platelet factor 3 availability (Stypven time) and platelet aggregation as measured by $30-60 \mathrm{sec}$. $30-90 \mathrm{sec}$, or maximum aggregation. However, â significant correlation was obtained between platelet factor 3 availability (Stypven time) and percentage disaggregation $\left(r=+0.645^{\omega}\right.$ $P<0.05)$ as shown in Figure 3.

\section{Uraemic patients}

Twelve uraemic patients having a normal kaolin cephalin clotting time and a platelet-rich plasm platelet count within the normal range were chosen to show this relationship. The significan correlation found in normal controls between the Stypven time and percentage disaggregation was absent in uraemic patients $(\mathrm{r}=+0.389, \mathrm{P}<0.1) 8$ The results with eight of the 12 uraemic patient fell outside the $95 \%$ confidence limit of the normal, ie, they showed either prolonged Stypven? times or diminished disaggregation or both. 


\section{Discussion}

\section{PLATELET FUNCTION}

The role of platelets in haemostasis and thrombosis has become a subject of much interest in recent years and appropriate tests have been devised to measure platelet function in vitro. Platelet adhesiveness is a measure of the ability of platelets to adhere to a foreign surface, while platelet aggregation is the property of platelets to adhere to each other. Platelets also contribute to the coagulation mechanism through the release of platelet factor 3 which catalyses the formation of the intrinsic prothrombin activator. Aggregation, adhesion, and release of platelet factor 3 can therefore be considered as important platelet functions which can be assessed in the laboratory. An attempt has been made to find a relationship between these three functions in healthy subjects and in uraemic patients in whom a qualitative platelet defect has been recently recognized.

Platelet adhesiveness to glass appears to be mediated through the release of ADP from red cells during their passage through the glass bead column (Hellem, 1960 and 1964; Gaarder, Jonsen, Laland, Hellem, and Owren, 1961), a step which is followed by aggregation between the platelets themselves (Wright, 1941; Salzman, 1963). A relationship might therefore be anticipated between the results obtained in tests of platelet adhesiveness and those found in tests of ADP-induced aggregation. When the two types of tests were performed from the same blood sample in normal subjects, no correlation was found between platelet adhesiveness and platelet aggregation. However, platelet adhesiveness was found to be negatively correlated with the ability of platelets to disaggregate following the addition of ADP in the turbidimetric system, ie, the more adhesiveness, the less disaggregation. In the majority of uraemic patients a negative correlation between platelet adhesiveness and disaggregation was not found.

Adenosine diphosphate has been found to activate platelet factor 3 (Hardisty and Hutton, 1966b; Horowitz and Papayoanou, 1968) and kaolin makes platelet factor 3 available by a reaction which involves platelet aggregation and which is inhibited by ADP antagonists such as adenosine and AMP (Hardisty and Hutton, 1965 and 1966a). It is possible that kaolin acts by releasing ADP from platelets, resulting in platelet aggregation and availability of platelet factor 3 .

Hardisty and Hutton (1965 and 1966a), measured the changes in optical density and in the Stypven time of platelet-rich plasma aggregated by ADP; they found that aggregation is rapidly followed by a reduction in the Stypven time which reaches a maximum after 20 minutes. The effect on the Stypven time was found to depend on the rate, degree, and duration of platelet aggregation. They suggested that the membrane changes which lead to platelet aggregation also provide a catalytic surface for the interaction of ${ }_{\Omega}^{c}$ coagulation factors; inhibition of platelet aggre- $\overline{\overline{5}}$ gation by adenosine was associated with a pro- 0

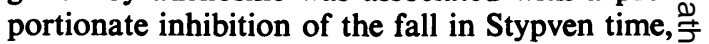
and phenothiazine derivatives, which inhibit ADP, $\frac{\text { ․ }}{}$ halted the effect of ADP on the Stypven time but $\vec{F}$ did not reverse it (Hardisty and Hutton, 1966b). The relationship found in the present communi- cation between platelet disaggregation and the $\frac{\bar{O}}{\bar{N}}$ Stypven time in normal controls may be explained in terms of the findings cited above. $\triangle$ Aggregated platelets disaggregate because of ${ }^{\mathscr{Q}}$ degradation of ADP by plasma and platelet $\vec{\circ}$ enzymes (Hellem and Owren, 1964; Salzman, Chambers, and Neri, 1966), and hence where $\vec{\omega}$ disaggregation is early and substantial, rapid degradation of ADP may be expected to have? occurred. Substances which accelerate ADP N degradation also reduce platelet factor 3 avail-ir ability (Hardisty and Hutton, 1966b; Horowitz + and Papyoanou, 1968) and therefore both reduced ${ }^{N}$ platelet factor 3 availability and accelerated dis-옥 aggregation might be expected in platelet-rich ${ }_{c}^{-}$ plasma with a high capacity to inhibit adenosine diphosphate.

In uraemic patients no correlation between $\vec{\theta}$ disaggregation and platelet factor 3 availability. was found, and most patients showed diminished disaggregation or prolonged Stypven time or both.

We are grateful to Professor E. M. McGirr for his interest in this work and to the Medical Research Council and Messrs Boehringer, Ingelheim for financial support.

\section{References}

Biggs, R., and Macfarlane, R. G. (1966). In Treatment of Haemo philia and other Coagulation Disorders, p. 344. Blackwell, Oxford.

Born, G. V. R., and Cross, M. J. (1963). The aggregation of blood platelets. J. Physiol. (Lond.), 168, 178-195.

Dacie, J. V. (1956). Practical Haematology, p. 49. Churchill, London.

Gaarder, A., Jonsen, J., Laland, S., Hellem, A., and Owren, P. A (1961). Adenosine diphosphate in red cells as a factor in the adhesiveness of human blood platelets. Nature (Lond.)
192,531-532.

Hardisty, R. M., and Hutton, R. A. (1965). The kaolin clottinto time of platelet-rich plasma; a test of platelet factor-3 avail ability.Brit. J. Haemat., 11, 258-268.

Hardisty, R. M., and Hutton, R. A. (1966a). Proc. Xth Congr. europ. Soc. Haemat., Strasbourg.

Hardisty, R. M., and Hutton, R. A. (1966b). Platelet aggregation and the availability of platelet factor-3. Brit. J. Haemat.

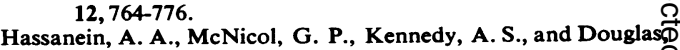
A.S. (1969). Unpublished observvations.

Hellem, A. J. (1960). The adhesiveness of human blood platelets vitro. Scand. J. clin. Lab. Invest., 12, Suppl. 51.

Hellem, A. J., and Owren, P. A. (1964). The mechanism of thछ hemostatic function of blood platelets. Acta haematois

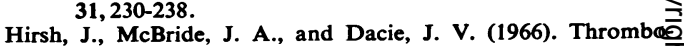
embolism and increased platelet adhesiveness in post, splenectomy thrombocytosis. Aust. Ann. Med., 15, 122-128. 
Horowitz, H. I., and Papayoanou, M. F. (1968). Activation of platelet factor-3 by adenosine 5' diphosphate. Thrombos. Diathes. haemorrh. (Stuttg.), 19, 18-28.

Lewis, J. H., Zucker, M. B., and Ferguson, J. H. (1956). Bleeding tendency in uremia. Blood, 11, 1073-1076.

Rath, C. E., Mailliard, J. A., and Schreiner, G. E. (1957). Bleeding tendency in uremia. New Engl. J. Med., 257, 808-811.

Salzman, E. W. (1963). Measurement of platelet adhesiveness. A simple in vitro technique demonstrating an abnormality in von Willebrand's disease. J. Lab. clin. Med., 62, 724-735.

Salzman, E. W., Chambers, D. A., and Neri, L. L. (1966). Possible mechanism of aggregation of blood platelets by adenosige diphosphate. Nature (Lond.), 210, 167-169.

Stewart, J. H., and Castaldi, P. A. (1967). Uremic bleeding:reversible platelet defect corrected by dialysis. Quart. on Med., 36, 409-423.

Spaet, T. H., and Cintron, J. (1965). Studies in platelet factor availability. Brit. J. Haemat., 11, 269-275.

Wright, H. P. (1941). The adhesiveness of blood platelets normal subjects with varying concentrations of ant coagulants. J. Path. Bact., 53, 255-262. 